\title{
Are COL4A1 and COL4A2 gene polymorphisms associated with cerebral palsy?
}

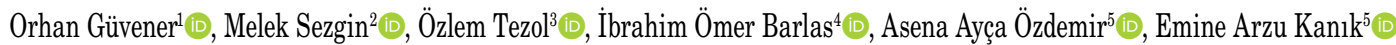 \\ 1Department of Physical Medicine and Rehabilitation, Mersin City Training and Research Hospital, Mersin, Turkey \\ ${ }^{2}$ Department of Physical Medicine and Rehabilitation, Mersin University Faculty of Medicine, Mersin, Turkey \\ ${ }^{3}$ Department of Pediatric, Mersin University Faculty of Medicine, Mersin, Turkey \\ ${ }^{4}$ Department of Medical Biology and Genetics, Mersin University Faculty of Medicine, Mersin, Turkey \\ ${ }^{5}$ Department of Biostatistics and Medical Informatics, Mersin University Faculty of Medicine, Mersin, Turkey
}

Received: October 25, 2019 Accepted: April 16, 2020 Published online: May 25, 2021

\begin{abstract}
Objectives: This study aims to investigate the association of COL4A1 and COL4A2 gene polymorphisms with susceptibility to risk of developing cerebral palsy (CP) and severity of CP.

Patients and methods: Between December 2016 and June 2017, a total of 176 patients with CP (101 males, 75 females; mean age $71.8 \pm 37.9$ months; range, 24 to 184 months) and age-, sex-, and ethnically-matched 178 (90 males, 88 females; mean age $69.3 \pm 55.2$ months; range, 24 to 214 months) controls were included. Two polymorphisms of COL4A1 (rs1961495) and COL4A2 (rs9521733) genes were typed from genomic deoxyribonucleic acid. Genotype distributions and allelic frequencies were compared between the patient and control groups. Gross Motor Function Classification System, the use of medical drugs, type of involvement, number of affected limbs, accompanying conditions, birth weight, gestational age, and magnetic resonance imaging (MRI) findings were used to evaluate the disease severity and their relationships with the COL $4 A 1$ and COL4A2 gene polymorphisms.

Results: There was no statistically significant difference between the groups in terms of genotype distribution and allele frequency of COL4A1 and COL4A2 gene polymorphisms ( $\mathrm{p}>0.05$ ). In addition, there was no relationship between severity of CP and two gene polymorphisms $(\mathrm{p}>0.05)$. A significant association was detected between the COL4A2 polymorphism and growth retardation in CP. The TT genotype (57.1\%) and T allele (76.2\%) were higher, compared to CC (4.8\%) and CT genotypes (38.1\%) and C allele (23.8\%) in patients with CP with growth retardation ( $\mathrm{p}=0.03$ for genotype and $\mathrm{p}=0.01$ for allele frequency).

Conclusion: These findings suggest that COL4A1 and COL4A2 gene polymorphisms are not associated with susceptibility to CP in a group of Turkish populations, although COL4A2 gene polymorphism may be associated with growth retardation in patients with CP.
\end{abstract}

Keywords: Cerebral palsy, COL4A1, COL4A2, gene polymorphism.

Cerebral palsy $(\mathrm{CP})$ is defined as a group of nonprogressive permanent diseases which occurs in the developing fetal or infant brain. It is associated with movement and postural disorders, thereby, restricting daily living activities. ${ }^{[1]}$ The motor disorders of $\mathrm{CP}$ are often accompanied by sensory, perceptual, cognitive, communicative, behavioral, and secondary musculoskeletal problems. In many countries, $\mathrm{CP}$ is the most common cause of physical disability in childhood. It affects one newborn in every 500 births. The worldwide prevalence of $\mathrm{CP}$ is estimated at 17 million. ${ }^{[2]}$ Despite the improvement in perinatal care, this rate has remained stable for more than four decades. ${ }^{[3]}$

Although CP develops due to similar damages in similar brain areas, it may differ clinically. The reason for these differences is that $\mathrm{CP}$ is a multifactorial disease. It is a heterogeneous disease and its etiology

Corresponding author: Orhan Güvener, MD. Mersin Şehir Eğitim ve Araştırma Hastanesi, Fiziksel Tip ve Rehabilitasyon Kliniği, 33240 Toroslar, Mersin, Türkiye. e-mail: dr.orhanguvener@gmail.com 
has not been fully understood, yet. Recent studies have reported that genetic factors may be responsible in CP. Some of the genetic factors are polymorphic changes in genes. ${ }^{[4,5]}$ The prevalence of congenital anomalies has increased in CP patients. Previous studies have reported a significantly higher concordance rate for $\mathrm{CP}$ in monozygotic twins, compared to dizygotic twins. The risk of CP is more than 2.5 times in families with consanguineous marriage. It has been reported that $\mathrm{CP}$ cases have a familial clustering and several new single gene mutations have been detected in idiopathic $\mathrm{CP}$ pedigrees. All these factors strongly support the contribution of genetic factor in the etiology of CP. ${ }^{[6]}$ Genotypes that may be susceptible to cerebral injury have been studied in the literature. Relationships between hereditary thrombophilia polymorphisms, cytokine polymorphisms, and cerebral palsy have been investigated in previous studies. ${ }^{[7,8]}$

Basal membranes are highly specialized extracellular matrix which can change cellular behavior to regulate tissue development, function, and repair. Type IV collagens are the main components of basal membranes and are encoded by six genes found in three different chromosomes. In humans, COL4A1 and COLAA2 are located on chromosome 13, COL4A3 and COL4A4 are located on chromosome 2, and COL4A5 and COL4A6 are located on chromosome X. ${ }^{[9]}$ The COL4A1, COL $4 A 2$ is the most important component of type IV collagen in the basal membrane and has been widely found in all tissues, including brain tissue. ${ }^{[10,11]}$ Mutation of COLAA1 is responsible for general and systemic basal membrane diseases presenting with various phenotypes, including neurological features such as stroke, infantile hemiparesis, and epilepsy. ${ }^{[12]}$ In COL4A2 mutations, similar to the COL4A1 mutations, pseudocysts in the cortex, focal hemorrhagic necroses surrounding small blood vessels can be observed. ${ }^{[13]}$

Due to the fact that $\mathrm{CP}$ is a multifactorial and heterogeneous disease, it is important to clarify the underlying genetic factors. In addition, the association of the characteristics of the disease with the genotype may be important for prognosis. In the present study, we hypothesized that COL4A1 rs1961495 and COL4A2 rs9521733 gene polymorphisms may be associated with the risk of development of $\mathrm{CP}$ and/or phenotype and clinical severity of $\mathrm{CP}$ in the light of all these data. We, therefore, aimed to investigate the association of COL4A1 and COL4A2 gene polymorphisms with susceptibility to risk of developing CP and severity of CP.

\section{PATIENTS AND METHODS}

The study was designed as a case-control trial. A total of 276 patients diagnosed with CP and followed at Mersin University Faculty of Medicine, Department of Physical Medicine and Rehabilitation between December 2016 and June 2017 were included in the study. The control group was composed of 200 individuals who were referred to the Children's Health Department of the institution and fulfilled inclusion criteria. Age and sex were matched with the propensity score method and 176 children (101 males, 75 females; mean age $71.8 \pm 37.9$ months; range, 24 to 184 months) for the patient group and 178 children (90 males, 88 females; mean age $69.3 \pm 55.2$ months; range, 24 to 214 months) for the control group were included in the study. Inclusion criteria for the patient group were as follows: having diagnosed with $\mathrm{CP}$ by the pediatric neurologist based on medical history, clinical, and imaging findings; age < 18 years; and having consent from his/her parents or legal guardians to participate in the study. Inclusion criteria for the control group were as follows: being healthy and age $<18$ years; having no medical or family history of congenital musculoskeletal disease, neurological disease, metabolic/endocrine disease, hematological disease or malignancy; and having consent from his/her parents or legal guardians to participate in the study. A written informed consent was obtained from each parent and/or his/her or legal guardians. The study protocol was approved by the Ethics Committee of Mersin University. The study was conducted in accordance with the principles of the Declaration of Helsinki.

All participants were evaluated in terms of age, sex, birth weight, gestational age, medications, and history of operation. The patient group was also evaluated in term of prenatal, natal, and postnatal risk factors, presence of accompanying problems such as epilepsy, mental retardation, visual and hearing impairment in their families, and presence of consanguineous marriage among the parents. In the examination of the patients, the presence of accompanying problems such as speech disorder, dysphagia, chewing and swallowing difficulties, mental retardation, epilepsy, growth and development retardation, sleep problems, tooth and gum problems, skeletal deformities and gross motor levels based on the Gross Motor Function Classification System (GMFCS), muscle tone, type of involvement, number of affected extremities, the use 
of medical drugs, and cerebral magnetic resonance imaging (MRI) findings were recorded.

\section{Molecular analysis}

A blood sample was drawn from each participant. Venous blood samples were collected in ethylenediaminetetraacetic acid (EDTA)-containing tubes. Deoxyribonucleic acid (DNA) was extracted from the whole blood. Genetic analysis was performed in Medical Biology and Genetics Department of Mersin University Faculty of Medicine.

\section{Genotypic analysis of COL4A1 (rs1961495) and COL4A2 (rs9521733) polymorphisms}

The genotyping of analysis of the COL $4 A 1$ (rs1961495) and COL4A2 (rs9521733) polymorphisms were performed using a full-blood commercial kit, High Pure PCR Template Preparation Kit (Roche Applied Science, Penzberg, Germany). The polymorphisms of the COL4A1 gene (rs196149) and COL4A2 gene (rs9521733) were performed using a pre-designed LightSNIP assay (TIB Molbiol, Berlin, Germany). Real-time polymerase chain reaction method (RT-PCR) was used for single nucleotide polymorphism (SNP) amplification experiment. The SNP amplification assays were performed according to the manufacturer's instructions. In brief, $20 \mu \mathrm{L}$ of reaction solution containing $30 \mathrm{ng}$ of DNA was mixed with $10 \mu \mathrm{L}$ LightCycler Probe Master Mix (Roche Applied Science, Penzberg, Germany), $1 \mu \mathrm{L}$ of the pre-synthesized LightSNIP kit, $4 \mu \mathrm{L}$ of water and $5 \mu \mathrm{L}$ of DNA. The reaction conditions are composed of three steps: Denaturation, amplification, and melting curve. It was pre-denatured at $95^{\circ} \mathrm{C}$ for $10 \mathrm{~min}$. The amplification was, then, subjected to amplification at $95^{\circ} \mathrm{C}$ for $10 \mathrm{sec}, 60^{\circ} \mathrm{C}$ for 10 sec, and $72^{\circ} \mathrm{C}$ for $15 \mathrm{sec}$ for 45 times. Finally, the melting curve stage $\left(30 \mathrm{sec}\right.$ at $95^{\circ} \mathrm{C}, 120 \mathrm{sec}$ at $40^{\circ} \mathrm{C}$, and $75^{\circ} \mathrm{C}$ for $0 \mathrm{sec}$ ) was analyzed in the LightCycler 480 II RT-PCR System (Roche Applied Science, Penzberg, Germany). Melting temperatures for melting curve analysis of the COL $4 A 1$ variant were evaluated as a melting heat (TM) of $55.64^{\circ} \mathrm{C}$ for the CC genotype, a melting heat (TM) for the TT genotype of $61.00^{\circ} \mathrm{C}$, and heterozygous for both genotypes. For the COL4A2 variant, the melting temperature (TM) for the TT genotype was $56.47^{\circ} \mathrm{C}$, the melting temperature (TM) for the CC genotype was $63.92^{\circ} \mathrm{C}$, and heterozygous for both genotypes.

\section{Statistical analysis}

In the reference study, the incidence of COL $4 A 1$ (rs1961495) T allele in the control group was given as
$44.8 \%$ with an odds ratio of $1.387 \cdot{ }^{[3]}$ Accordingly, it was planned to enroll 173 individuals in the patient group, 173 individuals in the control group, and a total of a minimum of 346 individuals with $80 \%$ study power and 5\% type I error. In this study, 200 children were included in each group, and age and sex were matched with the propensity score method. Finally, 176 children for the patient group and 178 children for the control group were included in the study.

Statistical analysis was performed using the Statistica version 13.3 software (StatSoft Inc., OK, USA). Descriptive data were expressed in mean \pm standard deviation (SD) and median (min-max) or number and frequency. The Shapiro-Wilk test was used to check the normality of continuous variables. Accordingly, the Student's t-test was used to compare the mean of two independent groups. The chi-square test was used to analyze the relationship and distribution of categorical variables. The Cochran-Armitage trend test was used to determine the relationship of COL4A1 and COL4A2 gene polymorphisms with categorical variables. In case of significant correlation, two ratio comparisons were applied according to each genotype. For the COL4A1 and COL4A2 gene polymorphisms, the Hardy-Weinberg equilibrium (HWE) was investigated separately in the patient and control groups. A $p$ value of $<0.05$ was considered statistically significant.

\section{RESULTS}

Both groups were similar in terms of age and sex ( $p>0.05$, Table 1). The birth weight, gestational age, and maternal age at birth were smaller in the patient group ( $\mathrm{p}<0.001, \mathrm{p}<0.001$, and $\mathrm{p}=0.02$, respectively). The distribution of birth weight of the patient group is given in Figure 1. There was no statistically significant difference in the consanguineous marriage between the groups $(\mathrm{p}=0.16)$.

According to the conditions accompanying $\mathrm{CP}$, 57 (32.4\%) patients had speech disorder, 37 (21\%) had chewing difficulty in swallowing, 53 (30.1\%) had salivation problem, $53(30.1 \%)$ had mental retardation, 27 (15.3\%) had visual impairment, nine (5.1\%) had hearing impairment, 37 (21.1\%) had epilepsy, 62 (35.2\%) had strabismus, 21 (11.9\%) had growth retardation, $11(6.3 \%)$ had sleep problem, and $15(8.5 \%)$ had dental problems.

Of the patients with $\mathrm{CP}, 81 \%$ had spastic type, $12.5 \%$ had dyskinetic type, and $6.3 \%$ had hypotonic 


\begin{tabular}{|c|c|c|c|c|c|c|c|}
\hline \multicolumn{8}{|c|}{$\begin{array}{c}\text { TABLE } 1 \\
\text { Demographic and clinical characteristics }\end{array}$} \\
\hline & \multicolumn{3}{|c|}{ Patient group } & \multicolumn{3}{|c|}{ Control group } & \multirow[b]{2}{*}{$p$} \\
\hline & $\mathrm{n}$ & $\%$ & Mean \pm SD & $\mathrm{n}$ & $\%$ & Mean \pm SD & \\
\hline Age (month) & & & $71.8 \pm 37.9$ & & & $69.3 \pm 55.2$ & 0.62 \\
\hline Sex & & & & & & & 0.2 \\
\hline Male & 101 & 57.4 & & 90 & 50.6 & & \\
\hline Female & 75 & 42.6 & & 88 & 49.4 & & \\
\hline Gestational age & & & & & & & $<0.001$ \\
\hline$<28$ Week & 20 & 11.4 & & 0 & 0.0 & & \\
\hline 28-31 Week & 62 & 35.2 & & 0 & 0.0 & & \\
\hline 31-37 Week & 47 & 26.7 & & 14 & 7.9 & & \\
\hline >37 Week & 47 & 26.7 & & 164 & 92.1 & & \\
\hline Birth weight (g) & & & $2080.8 \pm 952.2$ & & & $3049.8 \pm 470.3$ & $<0.001$ \\
\hline Maternal age at birth (year) & & & $27.0 \pm 4.7$ & & & $27.1 \pm 4.3$ & 0.02 \\
\hline Relative marriage rate & 38 & 21.6 & & 28 & 15.7 & & 0.16 \\
\hline Type of CP & & & & & & & - \\
\hline Spastic CP & 143 & 81.3 & & - & - & & \\
\hline Dyskinetic CP & 22 & 12.5 & & - & - & & \\
\hline Hypotonic-ataxic CP & 11 & 6.3 & & - & - & & \\
\hline GMFCS & & & & & & & - \\
\hline Level 1 & 16 & 9.1 & & - & - & & \\
\hline Level 2 & 36 & 20.5 & & - & - & & \\
\hline Level 3 & 55 & 33 & & - & - & & \\
\hline Level 4 & 52 & 29.5 & & - & - & & \\
\hline Level 5 & 14 & 8 & & - & - & & \\
\hline Magnetic resonance imaging & & & & & & & - \\
\hline Normal & 31 & 17.6 & & - & - & & \\
\hline Abnormal & 145 & 82.4 & & - & - & & \\
\hline Accompanying & & & & & & & - \\
\hline Epilepsy & 37 & 21.1 & & - & - & & \\
\hline Speech disorder & 57 & 32.4 & & - & - & & \\
\hline Defect of vision & 27 & 15.3 & & - & - & & \\
\hline Hearing disorder & 9 & 8.1 & & - & - & & \\
\hline Mental retardation & 53 & 30.1 & & - & - & & \\
\hline Growth retardation & 21 & 11.9 & & - & - & & \\
\hline
\end{tabular}

- ataxic type. Sixteen (9.1\%) patients were in the GMFCS Stage 1, $36(20.5 \%)$ patients were in the GMFCS Stage 2, 58 (33\%) patients were in the GMFCS Stage 3, $52(29.5 \%)$ patients were in the GMFCS Stage 4 , and $14(8 \%)$ patients were in the GMFCS Stage 5.

Genotype frequencies of rs1961495 and rs9521733 showed no deviations from HWE either in patients or in controls. The frequencies of alleles and genotypes of rs1961495 of COL4A1 and rs9521733 SNPs of COL4A2 are listed in Tables 2, respectively. The COL4A1 and COL4A2 genotype distributions and allele frequencies were not significantly different between the groups $(\mathrm{p}=0.12$ and $\mathrm{p}=0.08$, respectively).

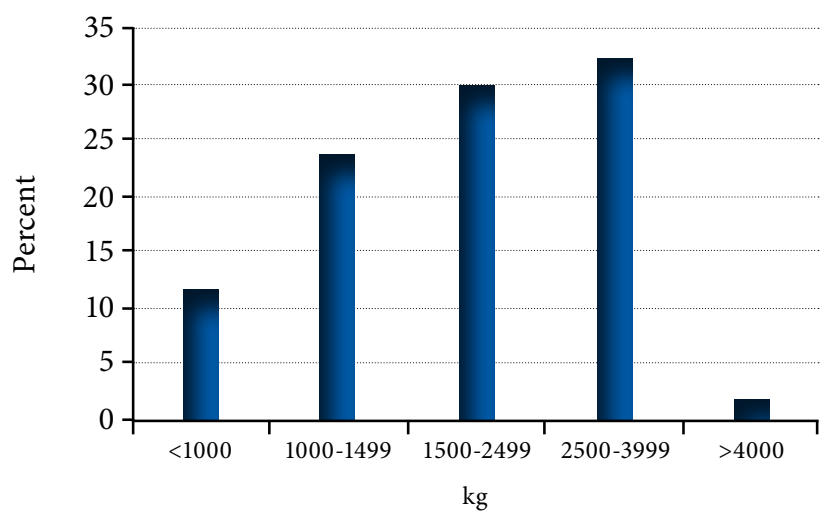

Figure 1. The distribution of birth weights of the patient group. 


\begin{tabular}{|c|c|c|c|c|c|c|}
\hline \multirow[b]{2}{*}{ Gene polymorphism } & \multirow[b]{2}{*}{ Genotype and allele } & \multicolumn{2}{|c|}{ Patient group } & \multicolumn{2}{|c|}{ Control group } & \multirow[b]{2}{*}{$p$} \\
\hline & & $\mathrm{n}$ & $\%$ & $\mathrm{n}$ & $\%$ & \\
\hline \multirow{5}{*}{ COL $4 A 1$} & $\mathrm{C} / \mathrm{C}$ & 133 & 75.6 & 124 & 69.7 & \multirow[t]{3}{*}{0.12} \\
\hline & $\mathrm{C} / \mathrm{T}$ & 42 & 23.9 & 48 & 27.0 & \\
\hline & $\mathrm{T} / \mathrm{T}$ & 11 & 0.6 & 6 & 3.3 & \\
\hline & $\mathrm{C}$ & 308 & 87.5 & 296 & 83.1 & \multirow[t]{2}{*}{0.1} \\
\hline & $\mathrm{T}$ & 44 & 12.5 & 60 & 16.9 & \\
\hline \multirow{5}{*}{ COL4A2 } & $\mathrm{C} / \mathrm{C}$ & 32 & 18.2 & 39 & 21.9 & \multirow[t]{3}{*}{0.08} \\
\hline & $\mathrm{C} / \mathrm{T}$ & 85 & 48.3 & 95 & 53.4 & \\
\hline & $\mathrm{T} / \mathrm{T}$ & 56 & 33.5 & 44 & 24.7 & \\
\hline & $\mathrm{C}$ & 149 & 42.3 & 178 & 49.0 & \multirow[t]{2}{*}{0.06} \\
\hline & $\mathrm{T}$ & 203 & 57.7 & 183 & 51.0 & \\
\hline \multirow{9}{*}{$C O L 4 A 1$ and $C O L 4 A 2$} & CCCC & 24 & 13.6 & 27 & 15.2 & \multirow[t]{9}{*}{0.44} \\
\hline & CCCT & 65 & 36.9 & 66 & 37.1 & \\
\hline & CCTT & 44 & 25 & 31 & 17.4 & \\
\hline & СТСС & 8 & 4.5 & 12 & 6.7 & \\
\hline & СТCT & 19 & 10.8 & 24 & 13.5 & \\
\hline & CTTT & 15 & 8.5 & 12 & 6.7 & \\
\hline & TTCC & 0 & 0 & 0 & 0 & \\
\hline & TTCT & 1 & 0.6 & 5 & 2.8 & \\
\hline & TTTT & 0 & 0 & 1 & 0.6 & \\
\hline
\end{tabular}

The distribution of genotypes coexistence of these two gene polymorphisms were examined between the groups and no statistically significant difference was found $(\mathrm{p}=0.44)$ (Table 2).

We investigated the relationship between the phenotype, severity of $\mathrm{CP}$ and genotype distribution, allele frequency in patients. To evaluate this, sex, gestational age, birth weight, type of $\mathrm{CP}$, number of affected extremities, MRI findings, medical treatment, risk factors, GMFCS, positive family history, problems associated with CP (speech disorder, chewing dysphagia, drooling, mental retardation, visual impairment, hearing impairment, epilepsy, growth retardation, sleep problem, dental gingival problems) were used. No statistically significant correlation was found ( $>0.05)$ (Table 3). There was a statistically significant relationship between growth retardation and COL4A2 polymorphism $(\mathrm{p}=0.03)$. TT genotype distribution and $\mathrm{T}$ allele frequency were significantly higher in $\mathrm{CP}$ children with growth retardation $(p=0.02$ and $p=0.01)$ (Table 4).

\section{DISCUSSION}

Cerebral palsy is a neurological syndrome which is a combination of symptoms, but not a disease. ${ }^{[13]}$ Although prematurity, hypoxia-ischemia, placental insufficiency, and prenatal infections are well-known causes of CP, for other patients, particularly those born at term and/or without a clear etiology identifiable by MRI, its etiology is still unclear. Some researchers
TABLE 3

The relation of gene polymorphisms with clinical and radiological findings

\begin{tabular}{|c|c|c|}
\hline & \multirow{2}{*}{$\frac{C O L 4 A 1}{p}$} & \multirow{2}{*}{$\begin{array}{c}C O L 4 A 2 \\
p\end{array}$} \\
\hline & & \\
\hline Gestational age & 0.48 & 0.22 \\
\hline Birth weight & 0.84 & 0.66 \\
\hline Sex & 0.25 & 0.34 \\
\hline Cerebral palsy type & 0.11 & 0.59 \\
\hline Number of limbs held & 0.83 & 0.32 \\
\hline \multicolumn{3}{|l|}{ MRI findings } \\
\hline White matter lesion & 0.72 & 0.09 \\
\hline Gray matter lesion & 0.95 & 0.80 \\
\hline Vascular/ventricular disorders & 0.63 & 0.71 \\
\hline Developmental disorder & 0.57 & 0.49 \\
\hline Medical treatment & 0.78 & 0.64 \\
\hline GMFCS & 0.54 & 0.68 \\
\hline \multicolumn{3}{|l|}{ Risk factors } \\
\hline Prenatal & 0.69 & 0.21 \\
\hline Natal & 0.87 & 0.35 \\
\hline Postnatal & 0.70 & 0.42 \\
\hline \multicolumn{3}{|l|}{ Accompanying } \\
\hline Speech disorder & 0.34 & 0.81 \\
\hline Chewing swallowing difficulty & 0.63 & 0.98 \\
\hline Salivation & 0.20 & 0.19 \\
\hline Mental retardation & 0.55 & 0.96 \\
\hline Vision disorder & 0.69 & 0.89 \\
\hline Hearing disorder & 0.94 & 0.28 \\
\hline Strabismus & 0.35 & 0.34 \\
\hline Epilepsy & 0.71 & 0.99 \\
\hline Sleep problem & 0.91 & 0.73 \\
\hline Dental gingival problems & 0.85 & 0.44 \\
\hline
\end{tabular}

MRI: Magnetic resonance imaging; GMFCS: Gross motor function classification system. 


\begin{tabular}{|l|ccccccc}
\multicolumn{7}{c}{ TABLE 4} \\
Relationship between growth retardation and polymorphisms, alleles distribution of COL4A1 and COL4A2 alleles
\end{tabular}

believe that genetic and epigenetic factors may be the cause of CP. Previous studies have shown that $30 \%$ of $\mathrm{CP}$ cases may be genetically inherited. ${ }^{[5]}$

There are studies investigating the association of collagen gene polymorphisms with many diseases. Apart from our study, the only study examining the relationship between $\mathrm{CP}$ and collagen gene polymorphisms was conducted in the Chinese population by $\mathrm{Bi}$ et al. ${ }^{[3]}$ They investigated only the relationship between the $\mathrm{CP}$ and six SNPs of the COL4A1 gene in their study including $351 \mathrm{CP}$ and 220 healthy controls. In this study, a statistically significant relationship was found between rs1961495, rs1411040 polymorphisms and CP. For the rs1961495 polymorphisms, the frequency of the $\mathrm{C}$ allele was found to be $63 \%$ in the CP group and $55 \%$ in the control group. The frequency of the $\mathrm{T}$ allele was $37 \%$ in the CP group and $45 \%$ in the control group $(\mathrm{p}=0.008)$. In the CP group, genotype distributions were found to be $40 \%$ for the CC genotype, $46 \%$ for the CT genotype, and $14 \%$ for the TT genotype. In the control group, genotype distributions were found to be $29 \%$ for CC genotype, $51 \%$ for the CT genotype, and $19 \%$ for the TT $(p=0.02)$. Similar to our study, in the aforementioned study, CC genotype and $\mathrm{C}$ allele frequencies were found to be higher in patients, and $\mathrm{CT}$, TT genotypes and $\mathrm{T}$ allele frequencies were found to be higher in the controls. Unlike our study, these rates were statistically significant. Bi et al. ${ }^{[3]}$ found that COL4A1 rs1961495, rs1411040 gene polymorphisms are associated with CP. However, they did not examine the relationship between the severity and phenotypic features of CP. We believe that this is one of the limitations of their study. When we examined the relationship between the phenotypic features and severity of CP with COL4A1 and COL4A2 gene polymorphisms, we found no statistically significant relationship between genotype distributions of each two gene polymorphisms and sex, gestational age, birth weight, risk factors, type of CP, GMFCS, MRI findings, family history of neurological diseases, and accompanying problems with $\mathrm{CP}(\mathrm{p}>0.05)$. We only found a statistically significant relationship between growth retardation and COL4A2 rs9521733 gene polymorphism $(\mathrm{p}=0.03)$. We found that TT genotype and $\mathrm{T}$ allele frequency were statistically significantly higher in patients with growth retardation $(\mathrm{p}=0.02$ and $\mathrm{p}=0.01$, respectively).

Type IV collagen is encoded by three paralog gene pairs, which encode six unique alpha chains to form heterodimers. The COL4A1 and COL4A2 are the most abundant component of type IV collagen. ${ }^{[3]}$ Therefore, we believe that our study would have a special place in the literature, since it is the first study to examine the coexistence of these polymorphisms, playing an important role in the synthesis of COL4A1 and COL4A2 peptides.

Yoneda et al. ${ }^{[14]}$ detected that COL4A1 mutations in patients with porencephaly, intracerebral calcification, focal cortical dysplasia, pontocerebellar atrophy, ocular abnormalities, myopathy, and high serum creatine kinase levels. Furthermore, in another study, it was reported that heterotrimer abnormalities of type IV collagen $\alpha 1 \alpha 1 \alpha 2$ caused porencephaly. ${ }^{[15]}$ The importance of screening for COL4A1 was also emphasized. ${ }^{[14,15]}$

Jeanne et al. ${ }^{[16]}$ reported that the mutations of COLAA1 and COL4A2 disrupted the secretion of 
proteins and caused cytotoxicity, and these mutations were associated with spontaneous intracerebral hemorrhage. Similar to the aforementioned studies, Shah et al. $^{[17]}$ reported that COL4A1 mutations could occur in children with infantile hemiplegia, quadriplegia, epilepsy and motor impairment, and that white matter changes on MRI might be helpful in the diagnosis in childhood. Rannikmäe et al. ${ }^{[18]}$ showed that there was a common relationship between the COL4A2 gene and symptomatic small vessel disease, particularly deep intracerebral hemorrhage. They also reported that these findings should be studied in non-European ethnic groups. Vahedi and Alamowitch $^{[19]}$ observed that COL4A1 mutations could cause multisystemic phenotypic features such as retinal arteriolar deposits, retinal hemorrhages, anterior segment dysgenesis, intracranial aneurysms, porencephaly, infantile hemiparesis, muscle cramps, optic nerve dysgenesis, and secondary glaucoma. In contrast to the aforementioned studies, in patients with $\mathrm{CP}$, we found no statistically significant difference in the relationship between both COL4A1 and COL4A2 gene polymorphisms with cerebral MRI findings. We believe that this may be due to the fact that our study was conducted in a small group of patients and our study population was in a different ethnic group than previous studies.

Nonetheless, there are some limitations in our study. Our study was conducted in a small population and a single center in southern Turkey. On the other hand, we believe that our study would contribute to the literature, as it is the first study to investigate the effects of COL4A1 and COL4A2 gene polymorphisms on phenotypic features of $\mathrm{CP}$, clinical severity, and risk of developing $\mathrm{CP}$ in our country and the world. Therefore, it can be speculated that this study would make significant contributions to the effect of COL4A1 and COL4A2 gene polymorphisms on the etiopathogenesis and clinic of CP.

In conclusion, in this study, we found no significant relationship between gene polymorphisms of COL4A1 rs1961495 and COL4A2 rs9521733 and the risk of developing CP. Apart from growth retardation, we found no significant correlation between COL4A1 rs1961495 and COL4A2 rs9521733 gene polymorphisms and phenotypic characteristics and disease severity of patients with CP. However, our study results showed a statistically significant relationship between growth retardation and COL4A2 rs9521733 gene polymorphism in patients with CP. We believe that TT genotype and $\mathrm{T}$ allele frequency are higher in patients with growth retardation and COL4A2 rs9521733 gene polymorphism may increase susceptibility to growth retardation in patients with $\mathrm{CP}$. Of note, further studies are needed to confirm these results in $\mathrm{CP}$ patients. These studies should be conducted in a large number of polymorphic genes in large sample groups and in similar and different populations.

Declaration of conflicting interests

The authors declared no conflicts of interest with respect to the authorship and/or publication of this article.

Funding

This study was supported by Mersin University Scientific Research Projects Unit with project number 2017-1-TP3-1996.

\section{REFERENCES}

1. Rosenbaum P, Paneth N, Leviton A, Goldstein M, Bax M, Damiano D, et al. A report: the definition and classification of cerebral palsy April 2006. Dev Med Child Neurol Suppl 2007;109:8-14.

2. Graham HK, Rosenbaum P, Paneth N, Dan B, Lin JP, Damiano DL, et al. Cerebral palsy. Nat Rev Dis Primers 2016;2:15082.

3. Bi D, Wang $H$, Shang $Q, X u ~ Y$, Wang $F$, Chen $M$, et al. Association of COL4A1 gene polymorphisms with cerebral palsy in a Chinese Han population. Clin Genet 2016;90:149-55.

4. Blackman JA, Gurka MJ, Bao Y, Dragulev BP, Chen WM, Romness MJ. Apolipoprotein E and functional motor severity in cerebral palsy. J Pediatr Rehabil Med 2009;2:67-74.

5. Fahey MC, Maclennan AH, Kretzschmar D, Gecz J, Kruer MC. The genetic basis of cerebral palsy. Dev Med Child Neurol 2017;59:462-9.

6. Moreno-De-Luca A, Ledbetter DH, Martin CL. Genetic insights into the causes and classification of cerebral palsies. Lancet Neurol 2012;11:283-92.

7. Gibson CS, MacLennan AH, Hague WM, Haan EA, Priest K, Chan A, et al. Associations between inherited thrombophilias, gestational age, and cerebral palsy. Am J Obstet Gynecol 2005;193:1437.

8. Gibson CS, MacLennan AH, Goldwater PN, Haan EA, Priest K, Dekker GA; South Australian Cerebral Palsy Research Group. The association between inherited cytokine polymorphisms and cerebral palsy. Am J Obstet Gynecol 2006;194:674.e1-11.

9. Mao M, Alavi MV, Labelle-Dumais C, Gould DB. Type IV Collagens and Basement Membrane Diseases: Cell Biology and Pathogenic Mechanisms. Curr Top Membr 2015;76:61-116.

10. Urabe N, Naito I, Saito K, Yonezawa T, Sado Y, Yoshioka H, et al. Basement membrane type IV collagen molecules in the choroid plexus, pia mater and capillaries in the mouse brain. Arch Histol Cytol 2002;65:133-43.

11. Sado Y, Kagawa M, Naito I, Ueki Y, Seki T, Momota R, et al. Organization and expression of basement membrane collagen IV genes and their roles in human disorders. J Biochem 1998;123:767-76. 
12. Plaisier E, Gribouval O, Alamowitch S, Mougenot B, Prost $\mathrm{C}$, Verpont $\mathrm{MC}$, et al. COL4A1 mutations and hereditary angiopathy, nephropathy, aneurysms, and muscle cramps. N Engl J Med 2007;357:2687-95.

13. Appleton RE, Gupta R. Cerebral palsy: not always what it seems. Arch Dis Child 2019;104:809-14.

14. Yoneda Y, Haginoya K, Kato M, Osaka H, Yokochi $\mathrm{K}$, Arai $\mathrm{H}$, et al. Phenotypic spectrum of COL $4 \mathrm{Al}$ mutations: porencephaly to schizencephaly. Ann Neurol 2013;73:48-57.

15. Yoneda Y, Haginoya K, Arai H, Yamaoka S, Tsurusaki Y, Doi $\mathrm{H}$, et al. De novo and inherited mutations in COL4A2, encoding the type IV collagen $\alpha 2$ chain cause porencephaly. Am J Hum Genet 2012;90:86-90.
16. Jeanne M, Labelle-Dumais C, Jorgensen J, Kauffman WB, Mancini GM, Favor J, et al. COL4A2 mutations impair COL4A1 and COL4A2 secretion and cause hemorrhagic stroke. Am J Hum Genet 2012;90:91-101.

17. Shah S, Ellard S, Kneen R, Lim M, Osborne N, Rankin J, et al. Childhood presentation of COL4A1 mutations. Dev Med Child Neurol 2012;54:569-74.

18. Rannikmäe K, Davies G, Thomson PA, Bevan S, Devan WJ, Falcone GJ, et al. Common variation in COL4A1/COL $4 A 2$ is associated with sporadic cerebral small vessel disease. Neurology 2015;84:918-26.

19. Vahedi K, Alamowitch S. Clinical spectrum of type IV collagen (COL4A1) mutations: a novel genetic multisystem disease. Curr Opin Neurol 2011;24:63-8. 